\title{
Development of Fully Degradable Phosphonium-Functionalized Amphiphilic Diblock Copolymers for Nucleic Acids Delivery
}

Yannick P. Borguet, ${ }^{\dagger}$ Sarosh Khan, ${ }^{\dagger}$ Amandine Noel, ${ }^{\dagger}$ Sean P. Gunsten, ${ }^{\ddagger}$ Steven L. Brody, ${ }^{\ddagger}$, Mahmoud Elsabahy, ${ }^{\dagger, \|}$ and Karen L. Wooley*, ${ }^{\dagger}+0$

${ }^{\dagger}$ Departments of Chemistry, Chemical Engineering, and Materials Science \& Engineering, and the Laboratory for Synthetic-Biologic Interactions, Texas A\&M University, College Station, Texas 77842, United States

${ }^{\ddagger}$ Department of Medicine, Washington University, St. Louis, Missouri 63110, United States

${ }^{\S}$ Department of Radiology, Washington University, St. Louis, Missouri 63110, United States

"Department of Pharmaceutics, Faculty of Pharmacy, Assiut International Center of Nanomedicine, Alrajhy Liver Hospital, Assiut University, Assiut 71515, Egypt

\section{Supporting Information}

ABSTRACT: To expand the range of functional polymer materials to include fully hydrolytically degradable systems that bear bioinspired phosphorus-containing linkages both along the backbone and as cationic side chain moieties for packaging and delivery of nucleic acids, phosphonium-functionalized polyphosphoester-block-poly(L-lactide) copolymers of various compositions were synthesized, fully characterized, and their self-assembly into nanoparticles were studied. First, an alkynefunctionalized polyphosphoester-block-poly(L-lactide) copolymer was synthesized via a one pot sequential ring opening polymerization of an alkyne-functionalized phospholane monomer, followed by the addition of L-lactide to grow the
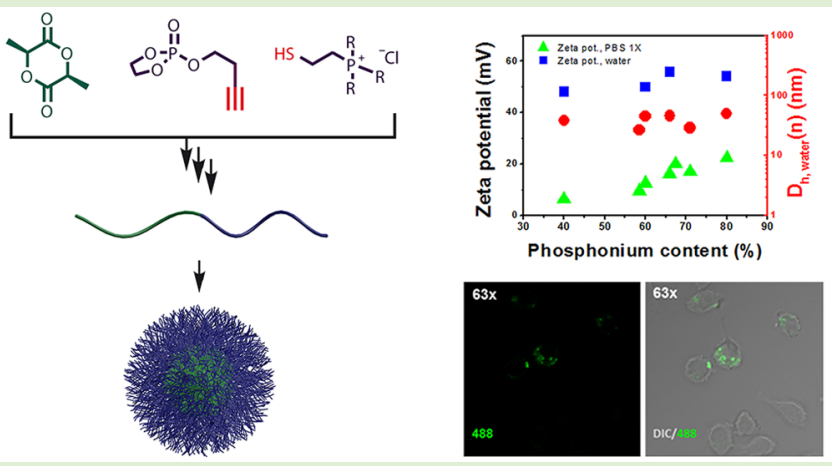
second block. Second, the alkynyl side groups of the polyphosphoester block were functionalized via photoinitiated thiol-yne radical addition of a phosphonium-functionalized free thiol. The polymers of varying phosphonium substitution degrees were self-assembled in aqueous buffers to afford formation of well-defined core-shell assemblies with an average size ranging between 30 and $50 \mathrm{~nm}$, as determined by dynamic light scattering. Intracellular delivery of the nanoparticles and their effects on cell viability and capability at enhancing transfection efficiency of nucleic acids (e.g., siRNA) were investigated. Cell viability assays demonstrated limited toxicity of the assembly to RAW 264.7 mouse macrophages, except at high polymer concentrations, where the polymer of high degree of phosphonium functionalization induced relatively higher cytotoxicity. Transfection efficiency was strongly affected by the phosphonium-tophosphate $\left(\mathrm{P}^{+} / \mathrm{P}^{-}\right)$ratios of the polymers and siRNA, respectively. The AllStars Hs Cell Death siRNA complexed to the various copolymers at a $\mathrm{P}^{+} / \mathrm{P}^{-}$ratio of 10:1 induced comparable cell death to Lipofectamine. These fully degradable nanoparticles might provide biocompatible nanocarriers for therapeutic nucleic acid delivery.

\section{INTRODUCTION}

Efficient delivery of genetic material intracellularly still represents one of the major bottlenecks to the wide applicability of nucleic acid-based therapies, despite progress reported during the past decade. ${ }^{1-6}$ Intracellular delivery of nucleic acid drugs, such as DNA and siRNA (short interfering RNA), can either trigger or knockdown the expression of specific proteins that are linked to several diseases. However, the poor cellular uptake of genetic material, due to its overall negative charge and rapid degradation of DNA/RNA by nucleases in biological media, still represent major challenges toward their successful cellular delivery.

Viral vectors have been used successfully to deliver genetic materials to cells, but have raised many safety concerns. ${ }^{7-9}$ On the other hand, nonviral vectors, such as cationic lipids and polymers, although less efficient than viral vectors, are able to protect and deliver genetic materials intracellularly via electrostatic interactions with the negatively charged nucleic acids to form what so-called lipoplexes and polyplexes, respectively. These cationic complexes can then undergo endocytosis and ultimately release the genetic materials in the cytosol. ${ }^{2-6,10-14}$

While most of the cationic systems described in the literature make use of ammoniums and other nitrogen-based functional groups as charged centers, some recent studies performed independently in the Long ${ }^{15,16}$ and Fréchet ${ }^{17}$ laboratories and others $^{18-20}$ have demonstrated the superiority of polymeric

Received: January 16, 2018

Revised: February 23, 2018

Published: March 11, 2018 
phosphonium salts over their ammonium counterparts in headto-head comparison experiments. The increased efficiency of phosphonium versus ammonium polycations was ascribed to their efficient cationic charge distribution (centered on the phosphorus atom, while distributed through adjacent carbons on the ammonium moiety), as demonstrated by calculations, ${ }^{21,22}$ which lead to stronger and more stable interactions with the negatively charged nucleic acids.

Our group has a long-standing interest in the design of biocompatible nanomaterials for various biomedical applications via tailoring their polymeric structures and macromolecular assembly. ${ }^{23-25}$ In addition, cellular delivery of nucleic acids has been achieved using shell-cross-linked nanoparticles, and we have initiated a transition from nondegradable polymer nanoparticles (e.g., poly(acrylamidoethylamine)- $b$-polystyrene) $)^{26-28}$ to partially degradable polymer systems (e.g., poly(acrylamidoethylamine)- $b$ polylactide). ${ }^{29}$ With the desire to move toward fully degradable polymer nanoparticle systems, we have recently reported the straightforward synthesis of versatile and degradable polymer platforms making use of polyphosphoester (PPE)-based block copolymers $^{30-32}$ and demonstrated their potential use as drug delivery vehicles in biomedical applications, such as the in vivo delivery of paclitaxel ${ }^{33}$ and antimicrobial agents to the lungs. ${ }^{34,35}$ We now report on the development of fully degradable phosphonium-functionalized amphiphilic diblock copolymers and their self-assembly into well-defined micellar systems for siRNA intracellular delivery.

\section{EXPERIMENTAL SECTION}

Materials. Dichloromethane, tetrahydrofuran (THF), and $\mathrm{N}, \mathrm{N}$ dimethylformamide (DMF) were purified by passage through a solvent purification system (JC Meyer Solvent Systems) and used as anhydrous solvents. The deuterated solvents $\left(\mathrm{CDCl}_{3}, \mathrm{CD}_{2} \mathrm{Cl}_{2}\right.$, DMSO- $d_{6}$ ) were products of Cambridge Isotopes Laboratories. All other reagents and solvents, tributylphosphine $\left(\mathrm{PBu}_{3}\right.$, Alpha Aesar), trimethylphosphine ( $\mathrm{PMe}_{3}$, Alpha Aesar), 2-chloroethanol (Alpha Aesar), thionyl chloride $\left(\mathrm{SOCl}_{2}\right.$, Aldrich), potassium thioacetate (KSAc, Alpha Aesar), anhydrous methanol (Alpha Aesar), 2,2dimethoxy-2-phenylacetophenone (DMPA, Aldrich), anhydrous dimethyl sulfoxide (ACROS, DMSO), Alexa Fluor 488 azide (A488, Life Technologies), copper bromide (CuBr, Aldrich), $N, N, N^{\prime}, N^{\prime}, N^{\prime \prime}$ pentamethyldiethylenetriamine (PMDETA, Aldrich), and ultrapure water (molecular biology grade, Quality Biological, Inc.) were used as received.

Characterization. ${ }^{1} \mathrm{H},{ }^{13} \mathrm{C}\left\{{ }^{1} \mathrm{H}\right\},{ }^{31} \mathrm{P}\left\{{ }^{1} \mathrm{H}\right\}$, and DQF COSY NMR spectra were recorded on Varian Mercury $300(300 \mathrm{MHz})$ or Varian Inova $500(500 \mathrm{MHz})$ spectrometers. The spectra were analyzed with MestReNova 6.0.2. Chemical shifts are listed in parts per million downfield from TMS and are referenced from the solvent peaks $\left({ }^{1} \mathrm{H}\right.$, $\left.{ }^{13} \mathrm{C}\left\{{ }^{1} \mathrm{H}\right\} \mathrm{NMR}\right)$ or from $\mathrm{H}_{3} \mathrm{PO}_{4}\left(85 \mathrm{wt} \% ;{ }^{31} \mathrm{P}\left\{{ }^{1} \mathrm{H}\right\} \mathrm{NMR}\right)$. IR spectra were recorded on a Shimadzu IR Prestige attenuated total reflectance Fourier-transform infrared spectrometer (ATR-FTIR) and analyzed using IR solution v.1.40 software.

Glass transition temperatures $\left(T_{\mathrm{g}}\right)$ and melting temperatures $\left(T_{\mathrm{m}}\right)$ were measured by differential scanning calorimetry (DSC) on a Mettler-Toledo DSC822 (Mettler-Toledo, Inc., Columbus, OH) under nitrogen with temperature gradients of $10{ }^{\circ} \mathrm{C} \cdot \mathrm{min}^{-1}$. Measurements were analyzed using Mettler-Toledo Star ${ }^{\mathrm{e}} \mathrm{v} .10 .00$ software. The $T_{\mathrm{g}}$ was taken as the midpoint of the inflection tangent upon the second heating scan $\left(-50\right.$ to $\left.100{ }^{\circ} \mathrm{C}\right)$, and the $T_{\mathrm{m}}$ is reported as the onset of the transition during the first heating cycle. Thermogravimetric analyses (TGA) were performed under an $\mathrm{Ar}$ atmosphere using a Mettler-Toledo model TGA/DSC 1, with a heating rate of $10^{\circ} \mathrm{C}$. $\min ^{-1}$.
Dynamic light scattering (DLS) measurements were performed using a Delsa Nano C (Beckman Coulter Inc., Fullerton, CA) equipped with a laser diode operating at $658 \mathrm{~nm}$. Scattered light was detected at an angle of $165^{\circ}$ and analyzed using a log correlator over 70 accumulations for a $0.5 \mathrm{~mL}$ sample in a glass sizing cell. Size measurements were performed in microbiology-grade ultrapure water at room temperature, unless otherwise specified. The calculations of the particle sizes and distribution averages were performed using the CONTIN routine using Delsa Nano 2.31 software. Unless otherwise specified, the particle sizes are reported as the average numberaveraged hydrodynamic diameters and standard deviations from a series of at least five measurements. The surface charge of the particles was evaluated through the measurement of their zeta potential $\left(\zeta_{\text {pot }}\right)$ by electrophoretic light scattering using a Delsa Nano $C$ particle analyzer equipped with a flow cell. Scattered light was detected at a $30^{\circ}$ angle. The zeta potential was measured in five different regions of the flow cell, and a weighed mean was calculated to account for the electroosmotic flow that is due to the surface charge of the cell walls. The zeta potentials are reported as the average and standard deviations from a series of at least three measurements.

Transmission electron microscopy (TEM) images were collected on a JEOL 1200 EX (Tokyo, Japan) operating at $100 \mathrm{kV}$ and micrographs were recorded at calibrated magnifications using a SLA-15C CCD camera. Samples for TEM were prepared as follows: $10 \mu \mathrm{L}$ of polymer or particle solution $\left(1 \mathrm{mg} \cdot \mathrm{mL}^{-1}\right)$ was deposited onto a carbon-coated copper grid, and after $2 \mathrm{~min}$, the excess solution was blotted with a piece of filter paper. The samples were then negatively stained with an aqueous solution of phosphotungstic acid (PTA, $1 \mathrm{wt} \%$ ). After $20 \mathrm{~s}$, the excess staining solution was blotted with a piece of filter paper. The samples were then dried under a gentle stream of dry nitrogen and analyzed within $24 \mathrm{~h}$.

Representative Synthesis of a Clickable Phosphonium Salt. Synthesis of (2-Hydroxyethyl)trimethylphosphonium Chloride (1a). A $50 \mathrm{~mL}$ flame-dried round-bottomed flask was filled with $6.6 \mathrm{~mL}$ of 2chloroethanol $(98 \mathrm{mmol})$ and capped with a rubber septum. The reagent was deoxygenated by bubbling nitrogen for $30 \mathrm{~min}$. Trimethylphosphine $(5.0 \mathrm{~g}, 70 \mathrm{mmol})$ was added dropwise under an inert atmosphere to the stirred 2-chloroethanol on an ice-water bath. The solution was stirred at $0{ }^{\circ} \mathrm{C}$ for $30 \mathrm{~min}$; then, a glass stopper was fitted and maintained in position with electrical tape and the vial was heated at $50{ }^{\circ} \mathrm{C}$ for $2 \mathrm{~d}$. The volatiles were evaporated in vacuo, and the white solid that formed was washed repeatedly with diethyl ether and finally dried under vacuum overnight to form the targeted structure as a white powder (5.5 g, 53\%). ${ }^{1} \mathrm{H}$ NMR (500 MHz, DMSO- $\left.d_{6}, \mathrm{ppm}\right) \delta 5.69(\mathrm{~s}, 1 \mathrm{H}), 3.82-3.67(\mathrm{~m}, 2 \mathrm{H}), 2.44(\mathrm{dt}, J=13.6$, $6.1 \mathrm{~Hz}, 2 \mathrm{H}), 1.89(\mathrm{~d}, J=15.1 \mathrm{~Hz}, 9 \mathrm{H}) .{ }^{13} \mathrm{C}$ NMR $(126 \mathrm{MHz}$, DMSO$\left.d_{6}, \mathrm{ppm}\right) \delta 54.2(\mathrm{~d}, \mathrm{~J}=7 \mathrm{~Hz}), 26.2(\mathrm{~d}, J=53 \mathrm{~Hz}), 8.3(\mathrm{~d}, J=54 \mathrm{~Hz})$. ${ }^{31} \mathrm{P}$ NMR $\left(202 \mathrm{MHz}, \mathrm{DMSO}-d_{6}, \mathrm{ppm}\right) \delta$ 28.6. FTIR (ATR) 3205, 2987-2809, 1287, 1056, 973, $856 \mathrm{~cm}^{-1}$.

(2-(Acetylthio)ethyl)trimethylphosphonium Chloride (2a). In the glovebox, (2-hydroxyethyl)trimethylphosphonium chloride (2.0 g, 13 mmol) was weighed in a Schlenk flask containing a stir bar and capped with a septum. Thionyl chloride $(4.6 \mathrm{~mL}, 64 \mathrm{mmol})$ was added dropwise at $0{ }^{\circ} \mathrm{C}$ under a flow of nitrogen with stirring. The resulting homogeneous solution was stirred for an additional $15 \mathrm{~min}$ at $0{ }^{\circ} \mathrm{C}$ and then heated to $75^{\circ} \mathrm{C}$ for $2 \mathrm{~h}$ with frequent venting under a flow of nitrogen. The excess of $\mathrm{SOCl}_{2}$ was evaporated under vacuum at $75^{\circ} \mathrm{C}$, and the resulting white solid was dried for one additional hour under vacuum at $75^{\circ} \mathrm{C}$. The resulting alkyl chloride was directly converted to the thioacetate without intermediate purification. Dry dichloromethane $(50 \mathrm{~mL})$ was added to the flask, and the formed suspension was transferred under nitrogen via cannula to a $250 \mathrm{~mL}$ roundbottomed flask containing a suspension of potassium thioacetate (5.5 $\mathrm{g}, 48 \mathrm{mmol}$ ) in $100 \mathrm{~mL}$ of dry dichloromethane. The reaction mixture was stirred at room temperature for $24 \mathrm{~h}$. The yellow supernatant was filtered $(0.45 \mu \mathrm{m}, \mathrm{NYLON})$, and the residual solid was extracted with dichloromethane $(2 \times 25 \mathrm{~mL})$. The organic fractions were combined and the volatiles were evaporated under reduced pressure. The resulting yellow solid was then washed with diethyl ether $(3 \times 50 \mathrm{~mL})$ and dried under high vacuum overnight to form an off-white 
hygroscopic solid (2.37 g, 87\%). ${ }^{1} \mathrm{H}$ NMR (500 MHz, $\left.\mathrm{CDCl}_{3}, \mathrm{ppm}\right) \delta$ 3.19-3.09 (m, 2H), 2.87-2.77 (m, 2H), $2.34(\mathrm{~s}, 3 \mathrm{H}), 2.24(\mathrm{~d}, J=14.4$ $\mathrm{Hz}, 9 \mathrm{H}) \cdot{ }^{13} \mathrm{C}$ NMR $\left(126 \mathrm{MHz}, \mathrm{CDCl}_{3}, \mathrm{ppm}\right) \delta 195.0(\mathrm{~s}), 30.6(\mathrm{~s})$, $23.4(\mathrm{~d}, J=49 \mathrm{~Hz}), 20.9(\mathrm{~s}), 7.2(\mathrm{~d}, J=53 \mathrm{~Hz}) .{ }^{31} \mathrm{P} \mathrm{NMR}(202 \mathrm{MHz}$, $\mathrm{CDCl}_{3}, \mathrm{ppm}$ ) $\delta$ 27.4. HRMS (ESI, $m / z$ ): 179.0665 (found), 179.0654 (calcd for $\mathrm{C}_{7} \mathrm{H}_{16} \mathrm{OPS}^{+}$). FTIR (ATR) 2965-2896, 1693, 1424, 1290, $1134,981,624 \mathrm{~cm}^{-1}$.

(2-Mercaptoethyl)trimethylphosphonium Chloride (3a). In the glovebox, (2-(acetylthio)ethyl)trimethylphosphonium chloride (500 $\mathrm{mg}, 2.33 \mathrm{mmol}$ ) was introduced into a $20 \mathrm{~mL}$ glass vial equipped with a stir bar and capped with a septum. The vial was removed from the glovebox and degassed $\mathrm{HCl}(4 \mathrm{~mL}$, aqueous, ca. $6 \mathrm{M})$ was added. The resulting clear yellow solution was stirred for $3 \mathrm{~h}$ at $65^{\circ} \mathrm{C}$ after which the byproducts and water were removed under high vacuum. The resulting solid was washed with dry THF $(3 \times 10 \mathrm{~mL})$ and finally dried under high vacuum to form the final product as a pale-yellow solid (386 mg, 96\%). ${ }^{1} \mathrm{H}$ NMR (500 MHz, $\left.\mathrm{CD}_{3} \mathrm{OD}, \mathrm{ppm}\right) \delta 2.93-$ $2.80(\mathrm{~m}, 2 \mathrm{H}), 2.71-2.59(\mathrm{~m}, 2 \mathrm{H}), 2.00-1.92(\mathrm{~m}, 9 \mathrm{H}) .{ }^{13} \mathrm{C}$ NMR $\left(126 \mathrm{MHz}, \mathrm{CD}_{3} \mathrm{OD}, \mathrm{ppm}\right) \delta 29.2(\mathrm{~d}, J=50 \mathrm{~Hz}), 17.6(\mathrm{~d}, J=4 \mathrm{~Hz})$, $8.5(\mathrm{~d}, J=55 \mathrm{~Hz}) .{ }^{31} \mathrm{P}$ NMR $\left(202 \mathrm{MHz}, \mathrm{CD}_{3} \mathrm{OD}\right) \delta 27.6$. HRMS (ESI, $m / z$ ): 137.0541 (found), 137.0548 (calcd for $\mathrm{C}_{5} \mathrm{H}_{14} \mathrm{PS}^{+}$). FTIR (ATR) 2966-2895, 2388, 1296, 1145, 980, 887, $778 \mathrm{~cm}^{-1}$.

Representative Photoinitiated Thiol-yne "Click" Functionalization of PBYP $_{50}-b-$ PLLA $_{50}$ with (2-Mercaptoethyl)trimethylphosphonium Chloride. The polymer $\left(\mathrm{PBYP}_{50^{-}} b\right.$ PLLA $_{50}, 40 \mathrm{mg}, 125 \mu \mathrm{mol}$ of alkyne groups) and the photoinitiator (DMPA, $20 \mathrm{mg}, 78 \mu \mathrm{mol}$ ) were solubilized in dry DMSO $(1.0 \mathrm{~mL}$ ), and the resulting solution was deoxygenated by bubbling with a stream of nitrogen for $15 \mathrm{~min}$ in the dark. A solution of (2-mercaptoethyl)trimethylphosphonium chloride $3 \mathrm{a}(43 \mathrm{mg}, 250 \mu \mathrm{mol}, 2$ equiv vs alkynes) in dry methanol $(1 \mathrm{~mL})$ was prepared in the glovebox and added to the polymer solution to form a light-yellow solution. The homogeneous reaction mixture was irradiated with a hand-held UV lamp $(365 \mathrm{~nm}, 6 \mathrm{~W})$ for $1 \mathrm{~h}$ in a cold room $\left(4{ }^{\circ} \mathrm{C}\right)$ and precipitated in diethyl ether $(40 \mathrm{~mL})$ twice from methanol $(2 \mathrm{~mL})$. The polymer was purified by dialysis against nanopure water (regenerated cellulose (RC) dialysis tubing, MWCO $=12-14 \mathrm{kDa}$ ) for $8 \mathrm{~h}$ in a cold room (4 ${ }^{\circ} \mathrm{C}$ ) with frequent solvent change. The resulting aqueous polymer solution was lyophilized to form the polymer as a white to light-yellow hygroscopic solid. All polymers were stored at $-20{ }^{\circ} \mathrm{C}$ and handled under a dry atmosphere. Polymer $\mathbf{M e}^{60}$ (60\% phosphonium functionalization): yield $64.2 \mathrm{mg} .{ }^{1} \mathrm{H}$ NMR $\left(300 \mathrm{MHz}\right.$, DMSO- $d_{6}$, ppm) $\delta 7.42(\mathrm{~s}, 0.1 \mathrm{H}), 6.51-6.20(\mathrm{~m}, 0.4 \mathrm{H}), 5.77-5.55(\mathrm{~m}, 0.4 \mathrm{H})$, $5.20(\mathrm{q}, J=7.0 \mathrm{~Hz}, 2.0 \mathrm{H}), 4.47-4.05(\mathrm{~m}, 6.0 \mathrm{H}), 3.27-2.55(\mathrm{~m}, 6.1$ $\mathrm{H}), 2.42(\mathrm{~d}, J=12.0 \mathrm{~Hz}, 0.74 \mathrm{H}), 1.97(\mathrm{~d}, J=12.0 \mathrm{~Hz}, 12.0 \mathrm{H}), 1.46$ $(\mathrm{d}, J=7.0 \mathrm{~Hz}, 6.3 \mathrm{H}) .{ }^{13} \mathrm{C}$ NMR $\left(126 \mathrm{MHz}, \mathrm{DMSO}-d_{6}, \mathrm{ppm}\right) \delta 169.2$, 127.0, 125.3, 124.8, 124.3, 68.7, 68.6, 66.34, 65.4, 63.1, 41.1, 36.9, 33.5, $33.1,29.9,24.7,23.5,23.4,23.0,21.8,16.5,7.5(\mathrm{~d}, J=52 \mathrm{~Hz}) .{ }^{31} \mathrm{P}$ NMR (121 MHz, DMSO- $d_{6}$, ppm) $\delta 28.1,27.9,27.7,-1.2,-1.3 . T_{\mathrm{m}}=$ $69{ }^{\circ} \mathrm{C}, \mathrm{T}_{\mathrm{g}}=54{ }^{\circ} \mathrm{C}, \mathrm{T}_{\mathrm{d}}{ }^{10 \%}=237^{\circ} \mathrm{C}, T_{\mathrm{p}}=300{ }^{\circ} \mathrm{C}, 32 \%$ weight remaining at $500{ }^{\circ} \mathrm{C}$.

Self-Assembly of the Amphiphilic Diblock Copolymers. The amphiphilic diblock copolymers were weighed (ca. $5.0 \mathrm{mg}$ ) under a dry nitrogen atmosphere, suspended into ultrapure water, or any otherwise specified buffers, to yield a final concentration of $1 \mathrm{mg}$. $\mathrm{mL}^{-1}$, and sonicated for $60 \mathrm{~min}$ over an ice-water bath $\left(0{ }^{\circ} \mathrm{C}\right)$ to form clear solutions. The assemblies were then characterized by TEM and DLS.

Degradation Study Monitored by NMR. The amphiphilic diblock copolymer $\mathbf{M e}^{60}$ (ca. $6 \mathrm{mg}$ ) was solubilized at a concentration of $10 \mathrm{mg} \cdot \mathrm{mL}^{-1}$ in a buffered $\mathrm{D}_{2} \mathrm{O}$ solution (MOPS, $50 \mathrm{mM}, \mathrm{pH}=7.4$, or acetate, $50 \mathrm{mM}, \mathrm{pH}=5.0)$ and sonicated for $1 \mathrm{~h}$ over an ice-water bath $\left(0{ }^{\circ} \mathrm{C}\right)$. The resulting solution was introduced in an NMR tube containing an internal reference insert $\left(\mathrm{PPh}_{3}\right.$ in DMSO- $\left.d_{6}\right)$. The tubes were maintained at the desired temperature $\left(37\right.$ or $\left.4{ }^{\circ} \mathrm{C}\right)$, and ${ }^{1} \mathrm{H}$ and ${ }^{31} \mathrm{P}$ spectra were recorded at timed intervals at room temperature. The signals arising from $\mathrm{PPh}_{3}$ were used as chemical shift and integration standards for the analysis of all ${ }^{1} \mathrm{H}$ and ${ }^{31} \mathrm{P}$ spectra.

Degradation Study Monitored by DLS. The amphiphilic diblock copolymer $\mathbf{M e}^{60}$ (ca. $6 \mathrm{mg}$ ) was solubilized at a concentration of $0.5 \mathrm{mg} \cdot \mathrm{mL}^{-1}$ in a buffered aqueous solution (MOPS, $50 \mathrm{mM}$, $\mathrm{pH}=$ 7.4 , or acetate, $50 \mathrm{mM}, \mathrm{pH}=5.0)$ and sonicated for $1 \mathrm{~h}$ over an ice water bath $\left(0{ }^{\circ} \mathrm{C}\right)$. The particle stock solution was split into 10 vials that were kept in a shaker at $37{ }^{\circ} \mathrm{C}$. Vials were removed from the shaker at timed intervals, and the samples were characterized in terms of their average number-averaged size distributions, scattered light intensities (attenuation corrected), and zeta potentials, as determined by DLS.

Cell Viability Assay. RAW 264.7 cells, a transformed mouse macrophage cell line, were purchased from the American Type Culture Collection (ATCC, Manassas, VA) and cultured in RPMI-1640 medium (Cellgro, Mediatech, Manassas, VA) supplemented with $10 \%$ fetal calf serum (Sigma-Aldrich) and $2 \mathrm{mM}$ L-glutamine. Cells were seeded $\left(2.5 \times 10^{4}\right.$ cells/well $)$ on black-walled, clear-bottomed, 96-well plates (BD Falcon, Franklin Lakes, NJ). After 24 h, diblock copolymers were diluted in media, added to the cells, and then incubated at $37{ }^{\circ} \mathrm{C}$ and $5 \% \mathrm{CO}_{2}$ for $24 \mathrm{~h}$. Cells were then equilibrated to room temperature for $30 \mathrm{~min}$ and washed three times with phosphate-buffered saline (PBS). To detect ATP activity, Cell-TiterGlo Reagent (Promega, Madison, WI) was added to cells and mixed on an orbital shaker for $2 \mathrm{~min}$ at room temperature. Cells were then incubated at room temperature for an additional $10 \mathrm{~min}$ and luminescence was detected with a Molecular Devices SpectraMax Gemini Microplate Spectrofluorometer (Sunnyvale, CA). Control cells treated with media only were used as the denominator to calculate percent of cell viability. Lipofectamine LTX (Invitrogen, Carlsbad, CA) was used according to the manufacturer instructions $(0.2 \mu \mathrm{L} /$ well) and its effect on cell viability was measured following the same procedures as that of the copolymers.

Flow Cytometry. RAW 264.7 cells were seeded $\left(5 \times 10^{4}\right.$ cells well) on 48-well plates. After $24 \mathrm{~h}$, diblock copolymers labeled with Alexa Fluor 488 dyes were diluted in media, added to the cells, and then incubated at $37^{\circ} \mathrm{C}$ and $5 \% \mathrm{CO}_{2}$ for 2 or $24 \mathrm{~h}$. Cells were scraped from the plates and washed three times with flow cytometry buffer composed of PBS ( $\mathrm{pH} 7.4$ ) containing $2 \%$ fetal bovine serum. Samples in triplicates were analyzed (10000 events per sample) using a FACSCalibur flow cytometer (BD Biosciences, San Jose, CA). Alexa Fluor 488 signal in cells incubated with copolymers was compared to cells alone to determine the percent of positive cells. Mean fluorescence intensity (MFI) was calculated using the geometric mean of the fluorescence distribution minus background. Both values were determined with CELLquest software (BD Biosciences).

Fluorescence Imaging. RAW 264.7 cells were seeded $\left(9 \times 10^{4}\right.$ cells/well) in a Lab-Tek, 8-well chamber slide (Nalge Nunc, Rochester, NY) that was previously coated with filter-sterilized 50 $\mu \mathrm{g} / \mathrm{mL}$ Type I rat tail collagen (BD Bioscience) in $0.02 \mathrm{~N}$ acetic acid. After 24 h, diblock copolymers labeled with Alexa Fluor 488 dyes were diluted in media, added to the cells, and then incubated at $37^{\circ} \mathrm{C}$ and $5 \% \mathrm{CO}_{2}$ for $4 \mathrm{~h}$. The cells were washed with PBS, fixed with $4 \%$ paraformaldehyde, covered with antifade medium (Vectashield, Vector Laboratories, Burlingame, CA), and mounted under a coverslip. Confocal microscopy imaging was performed using a Zeiss LSM 510 META laser scanning confocal instrument (Zeiss, Thornwood, NY). Cells were scanned along the $z$-axis to collect $10 \mu \mathrm{m}$ thick sections. Fluorescence and differential interference contrast (DIC) images were overlaid. Photomicrographs were globally adjusted for contrast and brightness using Photoshop (Adobe Systems, San Jose, CA).

Gel Shift Assays. The siRNA binding affinity of the different copolymers, $\mathbf{M e}^{40}, \mathbf{M e}^{60}$, and $\mathbf{M e}^{80}$ (40, 60, and $80 \%$ phosphonium functionalization, respectively), was investigated by gel shift assay. Agarose gels (1 wt\%) were prepared in Tris-acetate-EDTA buffer (BioRad Laboratories, Inc., Hercules, CA). The siRNA (5'-Cy3-(sense strand)-GGCCACAUCGGAUUUCACU, $M_{\mathrm{w}}=13814 \mathrm{~g} / \mathrm{mol}$, Dharmacon, Chicago, IL), either free or complexed to phosphoniumfunctionalized amphiphilic diblock copolymers (total molar concentration of the phosphonium in the polymers to phosphate groups in the siRNA $\left(\mathrm{P}^{+} / \mathrm{P}^{-}\right)$ratios ranging from 0.5 to $20(1.3 \mu \mathrm{g}$ siRNA $/ 25$ $\mu \mathrm{L} /$ well $)$ ), were mixed with glycerol $(20 \% v / v)$ prior to the electrophoresis. Gel electrophoresis was carried out using a horizontal apparatus at $100 \mathrm{~V}$ for $20 \mathrm{~min}$, and fluorescence imaging of the 
separated siRNA bands was performed using a ChemiDoc XRS imager and the data were analyzed by using Image Lab software (Bio-Rad Laboratories, Inc., Hercules, CA).

Death-siRNA Transfection Assays. OVCAR-3 cells $\left(5 \times 10^{3}\right.$ cells/well) were plated in 96-well plate in RPMI-1640 medium (20\% fetal bovine serum, and $1 \%$ penicillin/streptomycin). Cells were incubated at $37^{\circ} \mathrm{C}$ in a humidified atmosphere containing $5 \% \mathrm{CO}_{2}$ for $24 \mathrm{~h}$ to adhere. Then, the medium was replaced with a fresh medium 1 $\mathrm{h}$ prior to the addition of the siRNA ( $100 \mathrm{nM}$ final concentrations of AllStars Hs Cell Death- or negative control-siRNA (Qiagen, Valencia, CA)) mixed with copolymers, $\mathbf{M e}^{40}\left(25\right.$ and $50 \mu \mathrm{g} / \mathrm{mL}$ for $\mathrm{P}^{+} / \mathrm{P}^{-}$ ratios of 5 and 10 , respectively), $\mathbf{M e}^{60}$ (18 and $36 \mu \mathrm{g} / \mathrm{mL}$ for $\mathrm{P}^{+} / \mathrm{P}^{-}$ ratios of 5 and 10 , respectively), and $\mathbf{M e}^{80}\left(15\right.$ and $30 \mu \mathrm{g} / \mathrm{mL}$ for $\mathrm{P}^{+} /$ $\mathrm{P}^{-}$ratios of 5 and 10, respectively), or Lipofectamine 2000 . The cells were incubated with the various formulations for $48 \mathrm{~h}$ and then the medium was replaced with $100 \mu \mathrm{L}$ of fresh medium prior to the addition of $20 \mu \mathrm{L}$ of MTS combined reagent to each well (Cell Titer 96 Aqueous Non-Radioactive Cell Proliferation Assay, Promega Co., Madison, WI). The cells were incubated with the reagent for $2 \mathrm{~h}$ at 37 ${ }^{\circ} \mathrm{C}$ in a humidified atmosphere containing $5 \% \mathrm{CO}_{2}$ protected from light. Absorbance was measured at $490 \mathrm{~nm}$ using SpectraMax M5 (Molecular Devices, Sunnyvale, CA). The cell viability was calculated by estimating the relative cell viability of the cells treated with deathsiRNA to the negative control siRNA-loaded formulations. The Lipofectamine-siRNA complexes were prepared according to the manufacturer instructions and the transfection efficiency was measured following the same procedures of the siRNA complexes.

\section{RESULTS AND DISCUSSION}

Synthesis of Degradable Phosphonium-Functionalized Amphiphilic Diblock Copolymers. The degradable phosphonium-functionalized polyphosphoester- $b$-poly(L-lactide) amphiphilic copolymers were obtained in two steps using the strategy previously described by our group. ${ }^{32}$ First, an alkyne-functionalized polyphosphoester- $b$-poly(L-lactide) copolymer $\left(\mathrm{PBYP}_{50}-b\right.$-PLLA 50 ) was synthesized via a one-pot sequential ring-opening polymerization of an alkyne-functionalized phospholane monomer $\left(\mathrm{BYP}^{30,31}\right)$, followed by the addition of L-lactide to grow the second block (details are included in the Supporting Information and Figure S1). Subsequently, the functionalization of the alkynyl side groups of the PBYP block was performed via the photoinitiated thiolyne radical addition of a phosphonium-functionalized free thiol. This sequential approach allowed the elaboration of a small library of amphiphilic diblock copolymers that share a common backbone.

The mercaptoethyl-functionalized trialkylphosphonium salts $(3 \mathbf{a}, \mathbf{b})$ required for the thiol-yne click modification of the polyphosphoester block were synthesized in three steps from chloroethanol and the corresponding trialkylphosphines (Scheme 1). The nucleophilic substitution of trialkylphosphines with chloroethanol afforded the formation of the (2hydroxyethyl)trialkylphosphonium chloride salts that were converted to their thioacetates $\mathbf{2 a}$ or $\mathbf{2 b}$ by activation with thionyl chloride and subsequent substitution with potassium thioacetate. Finally, aqueous acidic treatment of the thioacetates under inert atmosphere formed the desired (2-mercaptoethyl)trialkylphosphonium salts (3a, $\mathbf{3} \mathbf{b})$ in good overall yields and purities. The tributylphosphonium derivative $(\mathbf{3 b})$ was isolated as an oil and was soluble in a number of organic solvents (chloroform, tetrahydrofuran, methanol, dimethyl sulfoxide), whereas the trimethylphosphonium salt $\mathbf{3 a}$ was obtained as a white crystalline solid with a melting point of approximately $129^{\circ} \mathrm{C}$ and was mostly soluble in methanol and water.
Scheme 1. Clickable (2-Mercaptoethyl)trialkylphosphonium Salts were Synthesized in Three Steps from Chloroethanol and the Parent Phosphine

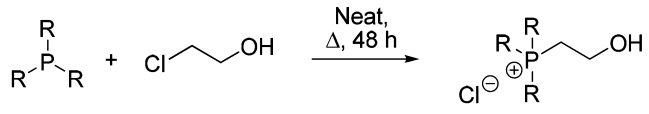

$$
\begin{aligned}
& \mathrm{R}=\mathrm{Me}(\mathrm{a}) \\
& =n-\mathrm{Bu}(\mathbf{b}) \\
& \begin{array}{l}
\text { 1a }(53 \%) \\
\text { 1b (81\%) }
\end{array} \\
& \begin{array}{l}
\text { 1. } \mathrm{SOCl}_{2} \text {, neat } \\
75^{\circ} \mathrm{C}, 2 \mathrm{~h} \\
\text { 2. } \mathrm{AcSK}, \mathrm{CH}_{2} \mathrm{Cl}_{2} \\
\text { r.t., } 24 \mathrm{~h}
\end{array}
\end{aligned}
$$

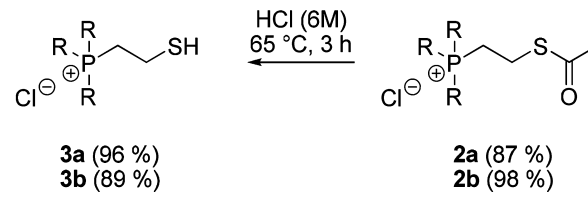

The hydrophobic PBYP $_{50}-b$-PLLA 50 diblock copolymer was modified by photoinitiated thiol-yne addition of thiolfunctionalized trialkylphospohonium salts $\mathbf{3} \mathbf{a}$ or $\mathbf{3} \mathbf{b}$ to form the corresponding phosphonium-functionalized amphiphilic diblock copolymers (Scheme 2). A preliminary experiment was conducted in the presence of 2 equiv of trimethylphosphonium salt 3a and 2,2-dimethoxy-2-phenylacetophenone (DMPA, $50 \mathrm{wt} \%$ vs the polymer) as a photoinitiator in a mixture of dimethyl sulfoxide and methanol $(1: 1, v / v)$ to ensure the solubility of all the components, under UV irradiation $(365 \mathrm{~nm})$ in a cold room for $1 \mathrm{~h}$. The product was purified by precipitation in diethyl ether followed by dialysis against nanopure water $(\mathrm{MWCO}=12-14 \mathrm{kDa})$ in the cold room to minimize any possible degradation (vide supra) and finally lyophilized to form a hygroscopic off-white solid that was stored under dry atmosphere at low temperature $\left(-20^{\circ} \mathrm{C}\right)$.

Proton and phosphorus NMR spectroscopies both indicate the successful attachment of trimethylphosphonium side groups onto the PBYP backbone (Figure 1 and Supporting Information). As mostly broad and overlapping signals were observed in the ${ }^{1} \mathrm{H}$ NMR spectrum of the copolymer in DMSO, a two-dimensional ${ }^{1} \mathrm{H}$ NMR experiment (COSY$\mathrm{DQF}$ ) was performed that allowed for the unambiguous attribution of the resolved signals in Figure 1 (Supporting Information, Figure S2). The intense signal centered at 1.97 $\mathrm{ppm}$ was attributed to the methyl protons of the trimethylphosphonium side groups and integrated for about $11 \mathrm{H}$ instead of an expected value of $18 \mathrm{H}$ when the integration of the methylene protons $\alpha$ to the phosphate group was set at $6 \mathrm{H}$. This observation denotes a less than quantitative functionalization of the PBYP block, which could be attributed either to the relatively low thiol-to-alkyne feed ratio of 2:1 that was initially investigated or to the low reactivity of the trimethylphosphonium-functionalized thiol during the click reaction caused by steric hindrance, or both. The two broad peaks centered around 6.30 and $5.60 \mathrm{ppm}$ (alkene region), integrating for approximately 0.40 each versus the methylene protons of the polymer backbone, indicate the presence of vinyl thioether substituents resulting from the addition of only one thiol molecule across the triple bond of the PBYP block. The ${ }^{1} \mathrm{H}$ NMR spectrum did not provide evidence for the presence of unreacted triple bonds along the PBYP backbone due to signal overlap; however, the two-dimensional spectrum 
Scheme 2. Photoinitiated Thiol-yne Addition of (2-Mercaptoethyl)trialkylphosphonium Salts to PBYP $50^{-} b$-PLLA 50 Copolymers Yields Phosphonium-Functionalized Amphiphilic Diblock Copolymers Presenting Varied Substitution Patterns

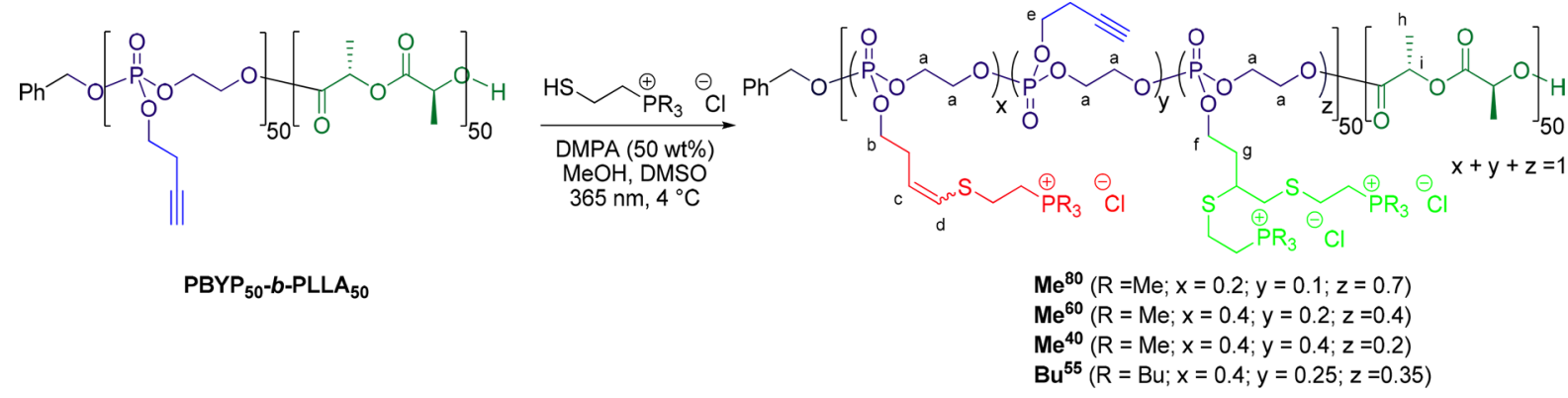

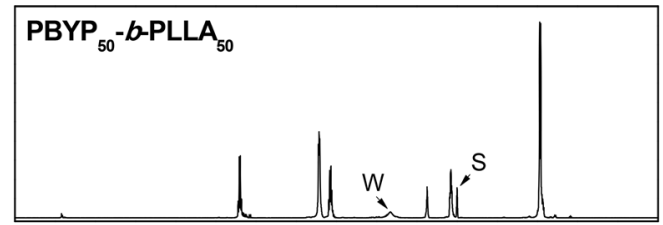

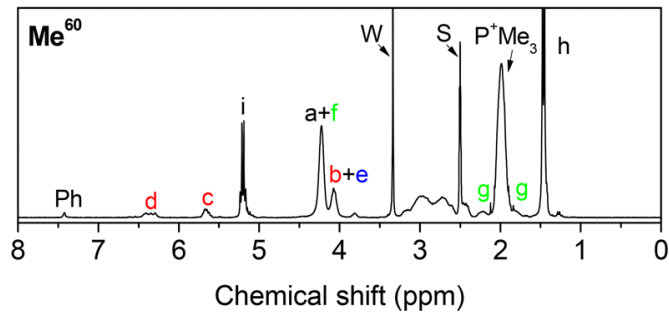

Figure 1. ${ }^{1} \mathrm{H}$ NMR spectra of the diblock copolymer before (upper panel) and after (lower panel) thiol-yne functionalization of the polyphosphoester block with a clickable phosphonium salt. W stands for water and $S$ stands for solvent (signal of the residual hydrogenated fraction present in DMSO- $\left.d_{6}\right)$. The labels of the proton peaks are explained in Scheme 2.

exhibited a cross correlation peak between the signals at 4.15 and $2.60 \mathrm{ppm}$, which is characteristic of the butynyl side groups found in the starting diblock copolymer (Supporting Information, Figure S2). As expected, the proton-decoupled ${ }^{31} \mathrm{P}$ NMR spectrum displayed a new set of signals centered at about $28.0 \mathrm{ppm}$, typical of a trimethylphosphonium derivative, along with another signal at about $-1.2 \mathrm{ppm}$ that was attributed to the polyphosphoester backbone (Supporting Information).

We further investigated the thiol-yne modification step by varying the reaction conditions to elaborate a small library of phosphonium-functionalized amphiphilic block copolymers with varied degrees of phosphonium functionalization along a shared polyphosphoester backbone (Table 1). To allow for an easy comparison between the samples, the notion of phosphonium content $\left(\% \mathrm{P}^{+}\right)$was introduced. The $\% \mathrm{P}^{+}$ parameter describes the actual extent of functionalization of the polyphosphoester block relative to a hypothetical fully functionalized one. The phosphonium content was thus calculated as follows: $\% \mathrm{P}^{+}=(x / 2+z) \times 100$, where $x$ and $z$ are the relative ratios of mono- and bis-adducts across the triple bonds of the PBYP block (Scheme 2), as determined by ${ }^{1} \mathrm{H}$ NMR spectroscopy (Table 1), based on the signal attribution presented above. In the case of the trimethylphosphonium derivative, we were able to achieve a rather high degree of functionalization $\left(\% \mathrm{P}^{+}=80 \%\right)$ by increasing both the reaction time and the thiol-to-alkyne feed ratio to 2.5:1, while a reduction of the feed ratio to $1: 1$ led to a phosphonium content of $40 \%$ (entries 1-3). Conversely, the reaction with (2mercaptoethyl)tributylphosphonium $3 \mathbf{b}$ led to only $55 \%$ functionalization of the PBYP block, despite the use of a rather high thiol-to-alkyne feed ratio of 5:1. This observation further highlights the sensitivity of thiol-yne/ene click reactions to steric constraints when used as a strategy for postpolymerization modification. ${ }^{36}$

Thermogravimetric analysis (TGA) of the phosphoniumfunctionalized diblock copolymers showed a concomitant increase in the thermal stability of the samples with the phosphonium content in the polyphosphoester block within the trimethylphosphonium functionalized series (1-3, Table 1, and Supporting Information, Figure S3). All three polymers from the trimethylphosphonium series $\left(\mathbf{M e}^{80}, \mathbf{M e}^{60}\right.$, and $\left.\mathbf{M e}^{40}\right)$ appeared as semicrystalline powders that exhibited a clear melting transition $\left(T_{\mathrm{m}}\right)$ on the first heating cycle during differential scanning calorimetry (DSC) measurements (Supporting Information, Figure S4). The increase in the $\% \mathrm{P}^{+}$ correlated to an increase in the observed melting transition temperature. It should also be noted that a second melting

Table 1. Characterization and Thermal Properties of Phosphonium-Functionalized Amphiphilic Diblock Copolymers Generated by Photoinitiated Thiol-yne Addition

\begin{tabular}{|c|c|c|c|c|c|c|c|c|c|}
\hline polymer & $\mathrm{R}$ & thiol/alkyne ${ }^{a}$ & $x^{b}$ & $y^{b}$ & $z^{b}$ & $\% \mathrm{P}^{+c}$ & $T_{\mathrm{g}}^{d}\left({ }^{\circ} \mathrm{C}\right)$ & $T_{\mathrm{m}}^{e}\left({ }^{\circ} \mathrm{C}\right)$ & $T_{\mathrm{d}}^{10 \% f}\left({ }^{\circ} \mathrm{C}\right)$ \\
\hline $\mathrm{Me}^{80}$ & $\mathrm{Me}$ & 2.5 & 0.2 & 0.1 & 0.7 & 80 & 59 & 80 & 247 \\
\hline$M e^{60}$ & & 2.0 & 0.4 & 0.2 & 0.4 & 60 & 54 & 69 & 237 \\
\hline $\mathrm{Me}^{40}$ & & 1.0 & 0.4 & 0.4 & 0.2 & 40 & 49 & 61 & 219 \\
\hline $\mathrm{Bu}^{55}$ & $\mathrm{Bu}$ & 5.0 & 0.4 & 0.25 & 0.35 & 55 & 6 & 37 & 234 \\
\hline
\end{tabular}

${ }^{a}$ Thiol/alkyne refers to the molar ratio of thiol reagent to alkynes from the PBYP block. ${ }^{b}$ The $x$ and $z$ ratios were determined by integration of the characteristic signals in the ${ }^{1} \mathrm{H}$ NMR spectra and represent the relative ratios of mono- and bis-adducts across the triple bonds of the PBYP block, and y was determined as follows: $y=1-x-z \cdot{ }^{c}$ The phosphonium content $\left(\% \mathrm{P}^{+}\right)$of the polyphosphoester block was defined as follows: $\% \mathrm{P}^{+}=(z+$ $x / 2) \times 100 .{ }^{d}$ Determined by DSC analysis during the second heating ramp. ${ }^{e}$ Determined by DSC during the first heating ramp. ${ }^{f}$ Determined by TGA. 
transition could be observed during the last heating cycle (ca. $120-130{ }^{\circ} \mathrm{C}$ ), but was relatively ill-defined because of the concomitant thermal decomposition of the sample (supported by discoloration of the samples). The glass transition $\left(T_{\mathrm{g}}\right)$ observed during the second heating cycle followed a trend similar to the $T_{\mathrm{m}}$, with $T_{\mathrm{g}}$ values comprised between 49 and 59 ${ }^{\circ} \mathrm{C}$ for $\mathbf{M e}^{40}$ and $\mathbf{M e}^{80}$, respectively. The melting transition was not easily identifiable in the tributylphosphonium-functionalized polymer, which could possibly be attributed to the relatively long alkyl chains leading to a poor packing of the polymer chains in the solid state.

Self-Assembly of the Amphiphilic Diblock Copolymers. The four amphiphilic diblock copolymers presented in Table 1 were hygroscopic and presented good solubility in nanopure water and phosphate-buffered saline (PBS) solutions. The polymer solutions were homogenized by sonication for $1 \mathrm{~h}$ over an ice-water bath $\left(0{ }^{\circ} \mathrm{C}\right)$ to minimize degradation, and clear solutions were formed for all three trimethylphosphonium functionalized copolymers. The tributylphosphonium-functionalized copolymer $\mathbf{B} \mathbf{u}^{\mathbf{5 5}}$ afforded a cloudy suspension even upon extended sonication. The ability of this polymer to form welldefined assemblies in aqueous solutions was, thus, not investigated further.

The hydrodynamic sizes and surface charges of the assemblies formed in aqueous solutions from the trimethylphosphonium-functionalized diblock copolymers $\mathbf{M e}^{40}, \mathbf{M e}^{60}$, and $\mathbf{M e}^{80}$ were assessed by dynamic light scattering (DLS) and the morphology of the assemblies was evaluated by bright-field transmission electron microscopy (TEM; Figure 2, and

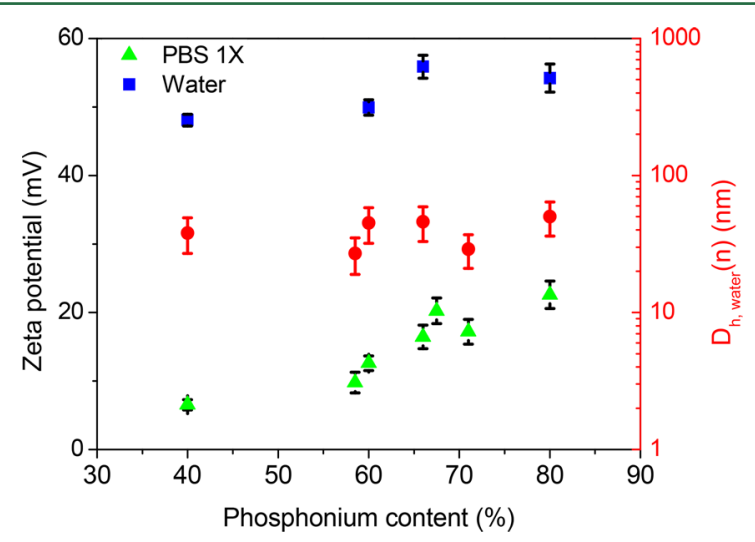

Figure 2. Effect of the phosphonium content $\left(\% \mathrm{P}^{+}\right)$in the polyphosphoester block on the sizes of the assemblies in water $\left(D_{\text {hwater }}(n)\right.$, red circle $)$ and their surface charges in nanopure water or PBS (blue square and green triangle, respectively).

Supporting Information, Figure S5). DLS demonstrated unimodal distributions with average number-averaged hydrodynamic radii $\left(D_{\mathrm{h}}(n)\right)$ ranging between 38 to $50 \mathrm{~nm}$ in water and slightly smaller in PBS (Supporting Information, Figure S5). As seen in Figure 2, no marked effect of the $\% \mathrm{P}^{+}$over the sizes of the aggregates was observed in aqueous solutions (red circles). The surface charges of the assemblies were evaluated in terms of their zeta potentials $\left(\zeta_{\text {pot }}\right)$, as determined by electrophoretic light scattering and was positive in all cases in nanopure water with values in the $50-55 \mathrm{mV}$ range and appeared to be only slightly affected by $\% \mathrm{P}^{+}$(Figure 2, blue squares). In PBS, the particle surface charge was greatly diminished, with zeta potentials ranging from about 5 to 25 $\mathrm{mV}$, which could be explained by the screening effect of the ions due to the high salt concentration $(150 \mathrm{mM} \mathrm{NaCl})$. Contrary to the nanopure water solutions, a nice correlation between the $\% \mathrm{P}^{+}$and the zeta potentials was observed in PBS solutions (Figure 2, green triangles).

Hydrolytic Degradation of the Diblock Copolymers. Polyphosphoesters are susceptible to degradation at the phosphoester linkages between the repeat units in the polymer backbone, leading to either main chain or side group cleavages. The degradation of polyphosphoesters has been studied extensively in the literature and occurs spontaneously in aqueous buffers $^{34,37}$ but can also be mediated by enzymes. ${ }^{38}$ Recent reports from our laboratory have investigated the degradation of self-assembled amphiphilic diblock copolymers made up of at least one polyphosphoester-based block using a range of characterization techniques (NMR spectroscopy, DLS, and mass spectrometry) and shown that the degradation rate was highly dependent on the nature of the side chain, ${ }^{34,39}$ as previously reported in the literature. In this work, the hydrolytic stability of polymer assemblies generated from phosphoniumfunctionalized amphiphilic diblock copolymers was evaluated in detail by multinuclear NMR spectroscopy, dynamic light scattering, and zeta potential measurements at acidic and neutral $\mathrm{pH}$ values $\left(\mathrm{pH}=5.0\right.$ and $\mathrm{pH}=7.4$, at $\left.37^{\circ} \mathrm{C}\right)$ using polymer $\mathbf{M e}^{60}$ as a model compound.

For the NMR study, polymer solutions $\left(10 \mathrm{mg} \cdot \mathrm{mL}^{-1}\right)$ were prepared by direct dissolution of copolymer $\mathbf{M e}^{60}$ in deuterated aqueous buffers (MOPS, $50 \mathrm{mM}, \mathrm{pH}=7.4$, or acetate, $50 \mathrm{mM}$, $\mathrm{pH}=5.0)$ and incubated at the desired temperature (4 or 37 $\left.{ }^{\circ} \mathrm{C}\right)$. The extent of hydrolysis of the charged block was evaluated at timed intervals by ${ }^{1} \mathrm{H}$ and ${ }^{31} \mathrm{P}$ NMR spectroscopies at room temperature (Supporting Information, Figure S6). The relative integration of the signals attributed to the methylene protons connected to the phosphate group (4.5-4.0 ppm, in ${ }^{1} \mathrm{H}$ NMR spectra) or the signal attributed to the phosphorus nuclei in the polymer backbone $\left(-1.2 \mathrm{ppm}\right.$, in ${ }^{31} \mathrm{P} \mathrm{NMR}$ spectra) were monitored versus an external chemical shift calibration ( ${ }^{31} \mathrm{P}$ NMR spectroscopy) and integration standard (Figure 3).

The degradation proceeded fast at $37^{\circ} \mathrm{C}$, independent of the $\mathrm{pH}$ values investigated ( 7.4 or 5.0 ), as evidenced by the rapid drop in the integration of the signals that are characteristic to the polyphosphoester block (both in ${ }^{1} \mathrm{H}$ and ${ }^{31} \mathrm{P}$ NMR spectra), with a half-life of about $24 \mathrm{~h}$, before reaching a plateau. Despite the apparent similarity in behavior at both $\mathrm{pH}$ values, it should be noted that macroscopic precipitation was observed within $20 \mathrm{~h}$ upon incubation at $\mathrm{pH}=7.4$, whereas it took $5 \mathrm{~d}$ at $\mathrm{pH}=5.0$. The major effect exerted by the $\mathrm{pH}$ of the incubation medium over the kinetics of degradation of polyphosphoesters has been previously reported in the literature ${ }^{34,37,39-43}$ and is discussed further below, in light of the DLS data. At lower temperature $\left(4{ }^{\circ} \mathrm{C}\right)$ the polyphosphoester backbone was substantially more stable at both $\mathrm{pH}$ values and most of the degradation that occurred was imputable to the fact that the NMR experiments were run at room temperature, which led to a faster apparent degradation.

The degradation process was also monitored by dynamic light scattering and zeta potential measurements. Polymer $\mathbf{M e}^{\mathbf{6 0}}$ was incubated in buffered aqueous solutions ( $50 \mathrm{mM}$, MOPS or acetate, $\mathrm{pH}=7.4$ or 5.0 , respectively) at $37{ }^{\circ} \mathrm{C}$, and the normalized scattered intensities (corrected for attenuation), zeta potentials, and number-averaged hydrodynamic size distributions were monitored over time (Figure 4). The degradation profiles obtained using light scattering techniques 
${ }^{1} \mathrm{H}$

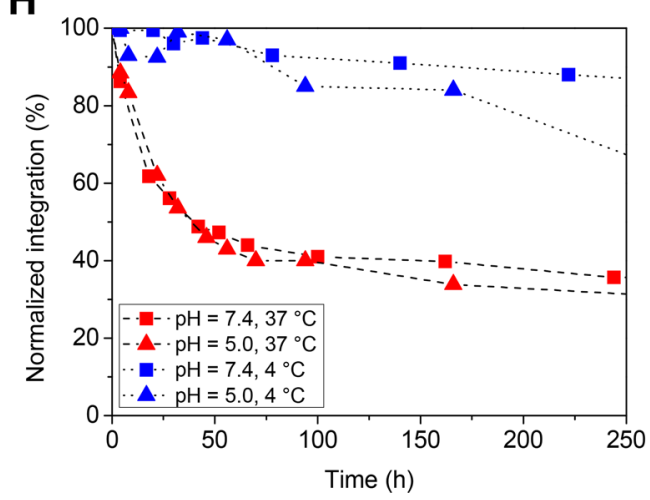

${ }^{31} \mathbf{P}$

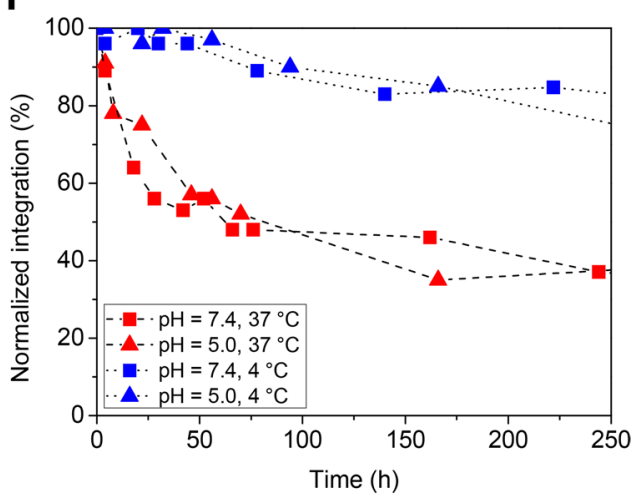

Figure 3. Evaluation of the degradation kinetics of diblock copolymer $\mathrm{Me}^{60}$ at $\mathrm{pH}=7.4\left(50 \mathrm{mM}\right.$ MOPS buffer in $\mathrm{D}_{2} \mathrm{O}$, squares $)$ or $\mathrm{pH}=5.0(50$ $\mathrm{mM}$ acetate buffer in $\mathrm{D}_{2} \mathrm{O}$, triangles) at 37 and $4{ }^{\circ} \mathrm{C}$ (red and blue, respectively). The reactions were monitored by integrating the signals of the methylene protons connected to the phosphate groups on the polyphosphoester block (left panel) or, alternatively, the signals arising from the phosphorus nuclei of the polyphosphate backbone (right panel) vs an internal reference $\left(\mathrm{PPh}_{3}\right.$ in DMSO- $d_{6}$ capillary insert) against time.
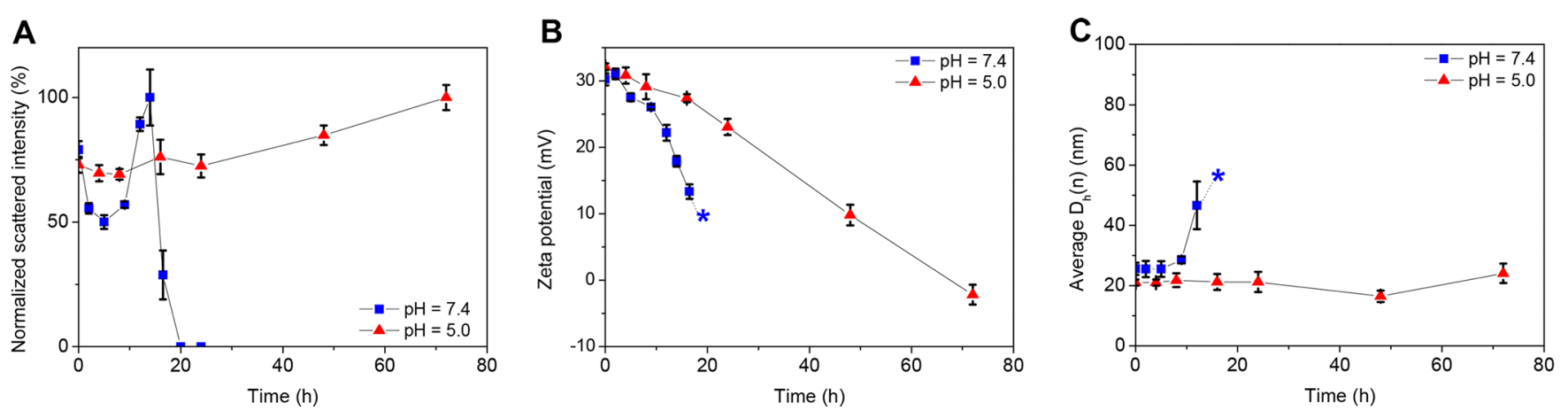

Figure 4. Evaluation of the hydrolytic stability of the micelles upon incubation in aqueous buffers $(50 \mathrm{mM}, \mathrm{MOPS}$ or acetate, $\mathrm{pH}=7.4$ or 5.0 , respectively) at $37{ }^{\circ} \mathrm{C}$ as monitored by DLS: (A) scattered light intensities, (B) zeta potentials, (C) average number-averaged hydrodynamic diameters and their standard deviations. Macroscopic precipitation was observed within $20 \mathrm{~h}$ when the degradation was performed at $\mathrm{pH}=7.4$, as denoted by *.

displayed a dichotomous behavior that contrasts starkly with the degradation profiles that were observed by NMR spectroscopy, in spite of similar macroscopic behavior in both sets of experiments. A precipitate formed within $16 \mathrm{~h}$ upon incubation at $\mathrm{pH}=7.4$, while incubation at $\mathrm{pH}=5.0 \mathrm{did}$ not lead to any precipitate over the course of the entire study (70 h). On the basis of the DLS data, it is hypothesized that the loss of solubility of the micellar assemblies upon incubation at $\mathrm{pH}=$ 7.4 might be attributed to cleavages along the polyphosphoester main chain. Such cleavages would lead to a rapid loss of electrostatic stabilization and also expose hydrophobic patches from the PLLA core and destabilize the assemblies that would then aggregate and ultimately precipitate. Interestingly, our group has recently reported a similar behavior for the hydrolytic degradation of a related carboxylate-functionalized PPE- $b$ PLLA copolymer upon incubation in buffered aqueous systems. ${ }^{34}$ In the present case, the fast drop in surface charge (Figure 4B) would support the hypothesis that main chain scissions are occurring predominantly over side chain cleavage. In a seminal study, Baran and Penczek showed, using NMR spectroscopy and titration techniques, that incubation $\mathrm{pH}$ value exerts a profound influence on the relative rate of hydrolysis of main chain versus side groups in methoxy-substituted polyphosphoesters. ${ }^{40}$ Importantly, they concluded that main chain cleavages were favored at higher $\mathrm{pH}$ values over side group cleavages. In the present work, at $\mathrm{pH}=5.0$, no macroscopic precipitation was noticed over the course of the study, while high scattering intensities and nearly constant particle sizes were observed, denoting the overall colloidal stability of the assemblies in solution. Interestingly, the surface charge of the assemblies decreased monotonously over time to attain neutral values within $72 \mathrm{~h}$ of incubation. Based on the above discussion and the early work from Baran and Penczek, we hypothesize that, at near-neutral $\mathrm{pH}$ values, the polymer assemblies degraded mostly through main chain cleavages leading to a rapid loss of colloidal stability and resulting in macroscopic precipitation, whereas under more acidic conditions $(\mathrm{pH}=5.0)$, cleavage of the side groups occurred faster. This cleavage pattern resulted in the formation of a negatively charged and hydrolytically more stable ${ }^{40,44}$ polyphosphate backbone that was still able to stabilize the assemblies in solution but led to a structure presenting an overall decrease in surface charge. Unfortunately, signal overlaps in the NMR spectra prevented a more in-depth investigation and no other meaningful information could be extracted from them to further support this hypothesis.

Feasibility of Utilizing the Diblock Copolymers as Carriers for Nucleic Acids (for Example, siRNA). The initial ability of nanoparticles toward nucleic acids delivery was tested via evaluating their cytotoxicity, cellular uptake, ability to electrostatically bind to a model siRNA, and finally by measuring the cell transfection efficiency of AllStars Hs Cell 
Death siRNA when complexed to the nanoparticles versus the Lipofectamine 2000 commercial transfection reagent. The effect of the phosphonium-functionalized diblock copolymers on viability of mouse macrophages (RAW 264.7) was evaluated at increasing polymer concentrations after incubation with the cells for $24 \mathrm{~h}$ (Figure 5). Worth mentioning is that the

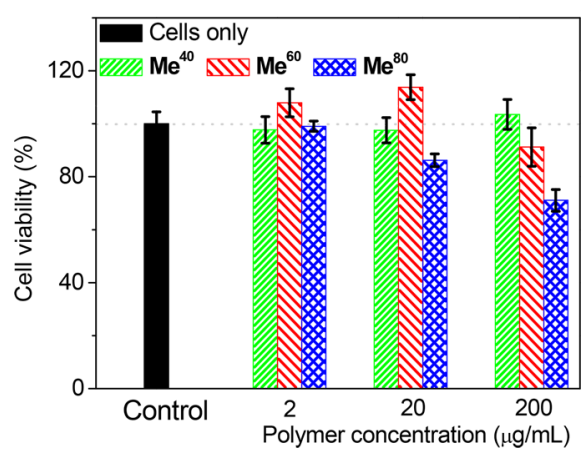

Figure 5. Cytotoxicity of the phosphonium-functionalized diblock copolymers toward mouse macrophage (RAW 264.7) cell line after 24 $\mathrm{h}$ incubation time. Control is Lipofectamine LTX, $0.2 \mu \mathrm{L} /$ well.

polymers might partially degrade over the $24 \mathrm{~h}$ period of incubation with the cells. An effect of the phosphonium content $\left(\% \mathrm{P}^{+}\right)$over the cytotoxicity was particularly obvious at high polymer concentration $\left(200 \mu \mathrm{g} \cdot \mathrm{mL}^{-1}\right)$, where $\mathbf{M e}^{40}$ displayed no toxicity, while $\mathbf{M e}^{80}$ led to about $30 \%$ cellular death under identical conditions. The low cytotoxicity pattern of the polymers is comparable to what has been previously observed with cationic degradable polyphosphoester micelles and, thus, confirms the higher biocompatibility of degradable polymers than the commercially available reagents (e.g., $\mathrm{IC}_{50}$ values for Lipofectamine and polyethylenimine were $31.4 \pm 6$ and $4.3 \pm 1$ $\mu \mathrm{g} / \mathrm{mL}$, when evaluated under identical conditions). ${ }^{45}$

To evaluate the cellular uptake of the polymers, an azidofunctionalized Alexa Fluor 488 dye was conjugated to the $\mathbf{M e}^{\mathbf{6 0}}$ polymer via copper-assisted azide-alkyne reaction, and the conjugation was confirmed by UV-vis and fluorescence spectroscopies and gel electrophoresis (Supporting Information, Figure S7). The cellular uptake of the cationic micelles was then investigated by flow cytometry and fluorescence imaging (Figure 6 and Supporting Information, Figure S8). The uptake of the $\mathbf{M e}^{60}$-Alexa Fluor 488 dye conjugated copolymer by RAW 264.7 mouse macrophages increased upon increasing the concentration of the polymers and incubation time with the cells (Figure 6). The uptake of the polymer was also confirmed and visualized using laser scanning confocal microscopy, where the images demonstrated an uptake (green fluorescence) after 4 $\mathrm{h}$ of incubation of the RAW 264.7 mouse macrophages with the $\mathbf{M e}^{60}-$ Alexa Fluor 488 conjugate (Supporting Information, Figure S8).

Complexation between the cationic polymers and siRNA allows for greater enzymatic stability and higher transfection efficiency, as compared to the free siRNA. ${ }^{46,47}$ The ability of copolymers $\mathrm{Me}^{40}, \mathbf{M e}^{60}$, and $\mathrm{Me}^{80}$ to efficiently complex Cy3labeled siRNA (molecular weight ca. $13814.3 \mathrm{~g} / \mathrm{mol}$ ) was investigated at a wide range of phosphonium-to-phosphorus $\left(\mathrm{P}^{+} / \mathrm{P}^{-}\right.$, polymer/siRNA $)$ratios. At a $\mathrm{P}^{+} / \mathrm{P}^{-}$ratio of 2 , the three copolymers were able to completely bind siRNA, as confirmed by the gel retardation assay (Supporting Information, Figure S9). Phosphonium-functionalized polymers were reported to have an increased efficiency of strong and stable binding to

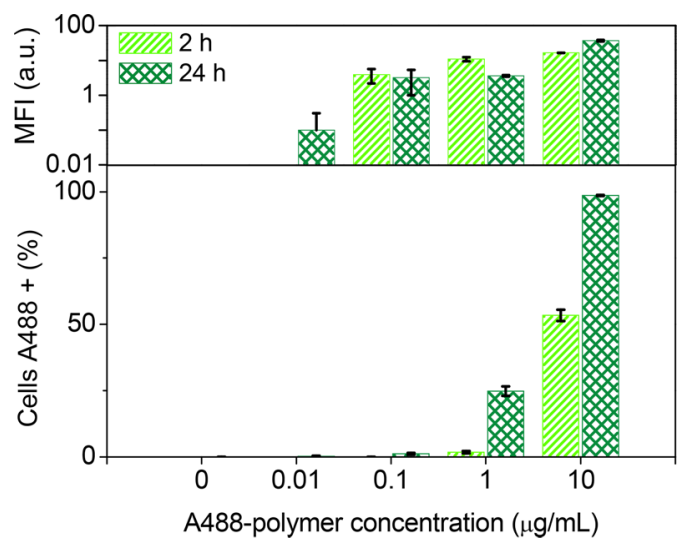

Figure 6. Concentration- and time-dependent cellular uptake of a $\mathbf{M e}^{60}$-Alexa Fluor 488 dye conjugated diblock copolymer in RAW 264.7 cells. The cells were incubated with the polymer at varied concentrations for 2 or $24 \mathrm{~h}$ and analyzed by flow cytometry (median fluorescence intensity, MFI, upper panel; percent cellular uptake, lower panel).

negatively charged nucleic acids, due to the efficient cationic charge distribution (i.e., centered on the phosphorus atom). ${ }^{17,21,22}$ The transfection efficiencies of AllStars Hs Cell Death siRNA, a set of siRNAs that target cell survival genes, complexed to the copolymers $\mathbf{M e}^{40}, \mathbf{M e}^{60}$, and $\mathbf{M e}^{80}$ were evaluated by measuring the effect of the complexes on the viability of human ovarian carcinoma cells (OVCAR-3). The cell survival was compared to each of the individual copolymers complexed with negative-control siRNA and Lipofectamine 2000 controls (Figure 7 ). The effect of the $\mathrm{P}^{+} / \mathrm{P}^{-}$ratio on the transfection efficiency of AllStars Hs Cell Death siRNA was also studied in OVCAR-3 cells. Complexes prepared at a $\mathrm{P}^{+} / \mathrm{P}^{-}$ ratio of 10 showed significantly higher transfection as compared to the transfection obtained at $\mathrm{P}^{+} / \mathrm{P}^{-}$ratio of 5 . The AllStars $\mathrm{Hs}$ Cell Death siRNA complexed to copolymers $\mathbf{M e}^{\mathbf{4 0}}, \mathbf{M e}^{\mathbf{6 0}}$, and $\mathbf{M e}^{80}$ at $\mathrm{P}^{+} / \mathrm{P}^{-}$ratio of 10 each induced similar levels of cell death that were slightly lower as compared to Lipofectamine 2000, which might be related to the higher stability of the complexes, partially retarding the release of siRNA intracellularly. ${ }^{48,49}$ We have previously demonstrated comparable transfection efficiency for the AllStars Hs Cell Death siRNA when it was complexed to nondegradable hierarchically assembled theranostic nanostructures. ${ }^{4,49}$ The polymersiRNA polyplexes were prepared immediately prior to the cellular transfection studies. As can be seen from Figure 6, uptake of the nanoparticles occurs mostly within the first $2 \mathrm{~h}$ of incubation with the cells and that the cellular uptake after $2 \mathrm{~h}$ was almost similar to the uptake after $24 \mathrm{~h}$. Based on the degradation studies, it is expected that the nanoparticles were able to deliver the complexed siRNA before significant degradation occurs. The phosphonium-functionalized fully degradable nanoparticles developed in the current study may have great potential for delivery of nucleic acid-based therapeutics by achieving transfection efficiency comparable to nondegradable commercially available transfection reagents and multifunctional nanoparticles previously developed by our group while being designed to degrade over time and to possess higher cellular biocompatibility.

\section{CONCLUSIONS}

A series of phosphonium-functionalized polyphosphoester- $b$ poly-L-lactide copolymers with increasing degrees of function- 


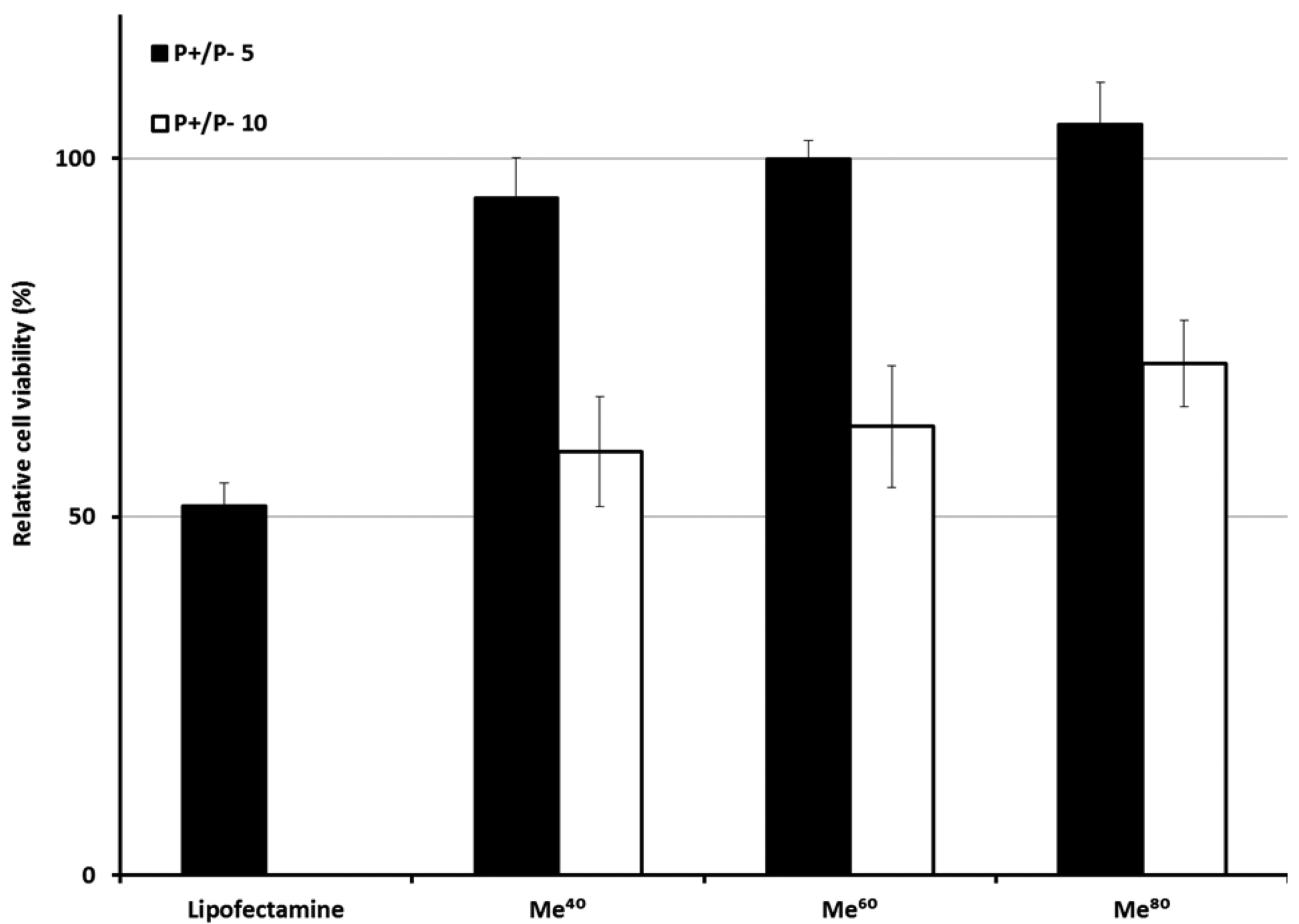

Figure 7. Transfection efficiency of cell-death siRNA complexed with Lipofectamine 2000, and copolymers $\mathbf{M e}^{40}, \mathbf{M e}^{60}$, and $\mathbf{M e}^{80}$ into OVCAR-3 cells at $\mathrm{P}^{+} / \mathrm{P}^{-}$ratios of 5 and 10 (mean $\pm \mathrm{SD}, n=3$ ). The effect of the $\mathrm{P}^{+} / \mathrm{P}^{-}$ratio on the transfection efficiency was determined by comparing the viabilities of cells treated with cell-death siRNA complexes vs negative control-siRNA complexes.

alization of the hydrophilic backbone with quaternary phosphonium salts were synthesized and fully characterized. The diblock copolymers were shown to self-assemble in aqueous buffers to form spherical nanosized assemblies with a core-shell structure as supported by DLS and TEM measurements. Detailed NMR spectroscopic and DLS studies revealed the putative degradation mechanism of those assemblies under hydrolytic degradation conditions. The positive surface charge of the assemblies as evaluated by zeta potentials allowed for the efficient complexation of nucleic acids (i.e., siRNA). The copolymer assemblies exhibited low toxicity on RAW 264.7 mouse macrophages, particularly, at low degrees of phosphonium functionalization. Transfection efficiency was strongly affected by the phosphonium-to-phosphate ratios $\left(\mathrm{P}^{+} / \mathrm{P}^{-}\right)$in OVCAR-3 cells and the AllStars Hs Cell Death siRNA complexed to the various copolymers at a $\mathrm{P}^{+} / \mathrm{P}^{-}$ratio of 10 was able to induce comparable cell death to Lipofectamine.

\section{ASSOCIATED CONTENT}

\section{S Supporting Information}

The Supporting Information is available free of charge on the ACS Publications website at DOI: 10.1021/acs.biomac.8b00069.

Detailed protocols for the synthesis of the phosphonium salts, block copolymer synthesis, modification, assembly, and characterization, as well as biological experiments (PDF).

\section{AUTHOR INFORMATION}

\section{Corresponding Author}

*E-mail: wooley@chem.tamu.edu.

\section{ORCID $\odot$}

Karen L. Wooley: 0000-0003-4086-384X

\section{Notes}

The authors declare no competing financial interest.

\section{ACKNOWLEDGMENTS}

We gratefully acknowledge financial support from the National Heart Lung and Blood Institute of the National Institutes of Health as a Program of Excellence in Nanotechnology (HHSN268201000046C), the National Science Foundation (DMR-1507429), and the Welch Foundation through the W. T. Doherty-Welch Chair in Chemistry (A-0001). The Microscopy and Imaging Center (MIC), the Laboratory for Biological Mass Spectrometry (LBMS/TAMU), and the Laboratory for Synthetic-Biologic Interactions (LSBI) at Texas A\&M University are also gratefully acknowledged.

\section{REFERENCES}

(1) Wu, S. Y.; Lopez-Berestein, G.; Calin, G. A.; Sood, A. K. RNAi Therapies: Drugging the Undruggable. Sci. Transl. Med. 2014, 6, 240 ps7.

(2) Wu, Y.; Smith, A. E.; Reineke, T. M. Lipophilic Polycation Vehicles Display High Plasmid DNA Delivery to Multiple Cell Types. Bioconjugate Chem. 2017, 28, 2035-2040.

(3) Jiang, Y.; Sprouse, D.; Laaser, J. E.; Dhande, Y.; Reineke, T. M.; Lodge, T. P. Complexation of Linear DNA and Poly(styrenesulfonate) with Cationic Copolymer Micelles: Effect of Polyanion Flexibility. J. Phys. Chem. B 2017, 121, 6708-6720.

(4) Dhande, Y. K.; Wagh, B. S.; Hall, B. C.; Sprouse, D.; Hackett, P. B.; Reineke, T. M. N-Acetylgalactosamine Block-co-Polycations Form Stable Polyplexes with Plasmids and Promote Liver-Targeted Delivery. Biomacromolecules 2016, 17, 830-840.

(5) Morsi, N. G.; Ali, S. M.; Elsonbaty, S. S.; Afifi, A. A.; Hamad, M. A.; Gao, H.; Elsabahy, M. Poly(glycerol methacrylate)-based degradable nanoparticles for delivery of small interfering RNA. Pharm. Dev. Technol. 2017, 1-13.

(6) Elzeny, H.; Zhang, F.; Ali, E. N.; Fathi, H. A.; Zhang, S.; Li, R.; El-Mokhtar, M. A.; Hamad, M. A.; Wooley, K. L.; Elsabahy, M. 
Polyphosphoester nanoparticles as biodegradable platform for delivery of multiple drugs and siRNA. Drug Des., Dev. Ther. 2017, 11, 483-496.

(7) Giacca, M.; Zacchigna, S. Virus-mediated gene delivery for human gene therapy. J. Controlled Release 2012, 161, 377-388.

(8) Wang, J.; Huang, S.-W.; Zhang, P.-C.; Mao, H.-Q.; Leong, K. W. Effect of side-chain structures on gene transfer efficiency of biodegradable cationic polyphosphoesters. Int. J. Pharm. 2003, 265, $75-84$.

(9) Vannucci, L.; Lai, M.; Chiuppesi, F.; Ceccherini-Nelli, L.; Pistello, $M$. Viral Vectors: a look back and ahead on gene transfer technology. New Microbiol 2013, 36, 1-22.

(10) Yue, Y.; Wu, C. Progress and perspectives in developing polymeric vectors for in vitro gene delivery. Biomater. Sci. 2013, 1, $152-170$.

(11) Ibraheem, D.; Elaissari, A.; Fessi, H. Gene therapy and DNA delivery systems. Int. J. Pharm. 2014, 459, 70-83.

(12) Wagner, E. Polymers for siRNA Delivery: Inspired by Viruses to be Targeted, Dynamic, and Precise. Acc. Chem. Res. 2012, 45, 10051013.

(13) Liu, X.-Q.; Sun, C.-Y.; Yang, X.-Z.; Wang, J. Polymeric-MicelleBased Nanomedicine for siRNA Delivery. Part Part Syst. Charact 2013, 30, 211-228.

(14) Islam, M. A.; Park, T. E.; Singh, B.; Maharjan, S.; Firdous, J.; Cho, M.-H.; Kang, S.-K.; Yun, C.-H.; Choi, Y. J.; Cho, C.-S. Major degradable polycations as carriers for DNA and siRNA. J. Controlled Release 2014, 193, 74-89.

(15) Hemp, S. T.; Smith, A. E.; Bryson, J. M.; Allen, M. H.; Long, T. E. Phosphonium-Containing Diblock Copolymers for Enhanced Colloidal Stability and Efficient Nucleic Acid Delivery. Biomacromolecules 2012, 13, 2439-2445.

(16) Hemp, S. T.; Allen, M. H.; Green, M. D.; Long, T. E. Phosphonium-Containing Polyelectrolytes for Nonviral Gene Delivery. Biomacromolecules 2012, 13, 231-238.

(17) Ornelas-Megiatto, C.; Wich, P. R.; Fréchet, J. M. J. Polyphosphonium Polymers for siRNA Delivery: An Efficient and Nontoxic Alternative to Polyammonium Carriers. J. Am. Chem. Soc. 2012, 134, 1902-1905

(18) Loczenski Rose, V.; Shubber, S.; Sajeesh, S.; Spain, S. G.; Puri, S.; Allen, S.; Lee, D. K.; Winkler, G. S.; Mantovani, G. Phosphonium Polymethacrylates for Short Interfering RNA Delivery: Effect of Polymer and RNA Structural Parameters on Polyplex Assembly and Gene Knockdown. Biomacromolecules 2015, 16, 3480-3490.

(19) Rose, V. L.; Mastrotto, F.; Mantovani, G. Phosphonium polymers for gene delivery. Polym. Chem. 2017, 8, 353-360.

(20) Jangu, C.; Long, T. E. Phosphonium cation-containing polymers: From ionic liquids to polyelectrolytes. Polymer 2014, 55, 3298-3304.

(21) Wang, S.-W.; Liu, W.; Colby, R. H. Counterion Dynamics in Polyurethane-Carboxylate Ionomers with Ionic Liquid Counterions. Chem. Mater. 2011, 23, 1862-1873.

(22) Liang, S.; O’Reilly, M. V.; Choi, U. H.; Shiau, H.-S.; Bartels, J.; Chen, Q.; Runt, J.; Winey, K. I.; Colby, R. H. High Ion Content Siloxane Phosphonium Ionomers with Very Low Tg. Macromolecules 2014, 47, 4428-4437.

(23) Elsabahy, M.; Wooley, K. L. Data Mining as a Guide for the Construction of Cross-Linked Nanoparticles with Low Immunotoxicity via Control of Polymer Chemistry and Supramolecular Assembly. Acc. Chem. Res. 2015, 48, 1620-1630.

(24) Elsabahy, M.; Li, A.; Zhang, F.; Sultan, D.; Liu, Y.; Wooley, K. L. Differential immunotoxicities of poly(ethylene glycol)- vs. poly(carboxybetaine)-coated nanoparticles. J. Controlled Release 2013, $172,641-652$.

(25) Elsabahy, M.; Samarajeewa, S.; Raymond, J. E.; Clark, C.; Wooley, K. L. Shell-crosslinked knedel-like nanoparticles induce lower immunotoxicity than their non-cross-linked analogs. J. Mater. Chem. B 2013, 1, 5241 .

(26) Zhang, K.; Fang, H.; Wang, Z.; Taylor, J.-S. A.; Wooley, K. L. Cationic shell-crosslinked knedel-like nanoparticles for highly efficient gene and oligonucleotide transfection of mammalian cells. Biomaterials 2009, 30, 968-977.

(27) Zhang, K.; Fang, H.; Wang, Z.; Li, Z.; Taylor, J.-S. A.; Wooley, K. L. Structure-activity relationships of cationic shell-crosslinked knedel-like nanoparticles: Shell composition and transfection efficiency/cytotoxicity. Biomaterials 2010, 31, 1805-1813.

(28) Shrestha, R.; Elsabahy, M.; Florez-Malaver, S.; Samarajeewa, S.; Wooley, K. L. Endosomal escape and siRNA delivery with cationic shell crosslinked knedel-like nanoparticles with tunable buffering capacities. Biomaterials 2012, 33, 8557-8568.

(29) Samarajeewa, S.; Ibricevic, A.; Gunsten, S. P.; Shrestha, R.; Elsabahy, M.; Brody, S. L.; Wooley, K. L. Degradable Cationic Shell Cross-Linked Knedel-like Nanoparticles: Synthesis, Degradation, Nucleic Acid Binding, and in Vitro Evaluation. Biomacromolecules 2013, 14, 1018-1027.

(30) Zhang, S.; Li, A.; Zou, J.; Lin, L. Y.; Wooley, K. L. Facile Synthesis of Clickable, Water-Soluble, and Degradable Polyphosphoesters. ACS Macro Lett. 2012, 1, 328-333.

(31) Zhang, S.; Zou, J.; Zhang, F.; Elsabahy, M.; Felder, S. E.; Zhu, J.; Pochan, D. J.; Wooley, K. L. Rapid and Versatile Construction of Diverse and Functional Nanostructures Derived from a Polyphosphoester-Based Biomimetic Block Copolymer System. J. Am. Chem. Soc. 2012, 134, 18467-18474.

(32) Lim, Y. H.; Heo, G. S.; Cho, S.; Wooley, K. L. Construction of a Reactive Diblock Copolymer, Polyphosphoester-block-Poly(1-lactide), as a Versatile Framework for Functional Materials That Are Capable of Full Degradation and Nanoscopic Assembly Formation. ACS Macro Lett. 2013, 2, 785-789.

(33) Zhang, F.; Zhang, S.; Pollack, S. F.; Li, R.; Gonzalez, A. M.; Fan, J.; Zou, J.; Leininger, S. E.; Pavía-Sanders, A.; Johnson, R.; Nelson, L. D.; Raymond, J. E.; Elsabahy, M.; Hughes, D. M. P.; Lenox, M. W.; Gustafson, T. P.; Wooley, K. L. Improving Paclitaxel Delivery: In Vitro and In Vivo Characterization of PEGylated Polyphosphoester-Based Nanocarriers. J. Am. Chem. Soc. 2015, 137, 2056-2066.

(34) Lim, Y. H.; Tiemann, K. M.; Heo, G. S.; Wagers, P. O.; Rezenom, Y. H.; Zhang, S.; Zhang, F.; Youngs, W. J.; Hunstad, D. A.; Wooley, K. L. Preparation and in Vitro Antimicrobial Activity of SilverBearing Degradable Polymeric Nanoparticles of Polyphosphoesterblock-Poly(1-lactide). ACS Nano 2015, 9, 1995-2008.

(35) Zhang, F.; Smolen, J. A.; Zhang, S.; Li, R.; Shah, P. N.; Cho, S.; Wang, H.; Raymond, J. E.; Cannon, C. L.; Wooley, K. L. Degradable polyphosphoester-based silver-loaded nanoparticles as therapeutics for bacterial lung infections. Nanoscale 2015, 7, 2265-2270.

(36) Lowe, A. B. Thiol-ene "click" reactions and recent applications in polymer and materials synthesis. Polym. Chem. 2010, 1, 17-36.

(37) Lim, Y. H.; Heo, G. S.; Rezenom, Y. H.; Pollack, S.; Raymond, J. E.; Elsabahy, M.; Wooley, K. L. Development of a Vinyl EtherFunctionalized Polyphosphoester as a Template for Multiple Postpolymerization Conjugation Chemistries and Study of Core Degradable Polymeric Nanoparticles. Macromolecules 2014, 47, 46344644.

(38) Wachiralarpphaithoon, C.; Iwasaki, Y.; Akiyoshi, K. Enzymedegradable phosphorylcholine porous hydrogels cross-linked with polyphosphoesters for cell matrices. Biomaterials 2007, 28, 984-993.

(39) Shen, Y.; Zhang, S.; Zhang, F.; Loftis, A.; Pavía-Sanders, A.; Zou, J.; Fan, J.; Taylor, J.-S. A.; Wooley, K. L. Polyphosphoester-Based Cationic Nanoparticles Serendipitously Release Integral BiologicallyActive Components to Serve as Novel Degradable Inducible Nitric Oxide Synthase Inhibitors. Adv. Mater. 2013, 25, 5609-5614.

(40) Baran, J.; Penczek, S. Hydrolysis of Polyesters of Phosphoric Acid. 1. Kinetics and the pH Profile. Macromolecules 1995, 28, 51675176.

(41) Wen, J.; Zhuo, R.-X. Preparation and characterization of poly(D,L-lactide-co-ethylene methyl phosphate). Polym. Int. 1998, 47, 503-509.

(42) Iwasaki, Y.; Nakagawa, C.; Ohtomi, M.; Ishihara, K.; Akiyoshi, K. Novel Biodegradable Polyphosphate Cross-Linker for Making Biocompatible Hydrogel. Biomacromolecules 2004, 5, 1110-1115. 
(43) Yang, X.-Z.; Wang, Y.-C.; Tang, L.-Y.; Xia, H.; Wang, J. Synthesis and characterization of amphiphilic block copolymer of polyphosphoester and poly(L-lactic acid). J. Polym. Sci., Part A: Polym. Chem. 2008, 46, 6425-6434.

(44) Zhang, S.; Wang, H.; Shen, Y.; Zhang, F.; Seetho, K.; Zou, J.; Taylor, J.-S. A.; Dove, A. P.; Wooley, K. L. A Simple and Efficient Synthesis of an Acid-Labile Polyphosphoramidate by OrganobaseCatalyzed Ring-Opening Polymerization and Transformation to Polyphosphoester Ionomers by Acid Treatment. Macromolecules 2013, 46, 5141-5149.

(45) Elsabahy, M.; Zhang, S.; Zhang, F.; Deng, Z. J.; Lim, Y. H.; Wang, H.; Parsamian, P.; Hammond, P. T.; Wooley, K. L. Surface charges and shell crosslinks each play significant roles in mediating degradation, biofouling, cytotoxicity and immunotoxicity for polyphosphoester-based nanoparticles. Sci. Rep. 2013, 3, 3313.

(46) Elsabahy, M.; Zhang, M.; Gan, S. M.; Waldron, K. C.; Leroux, J. C. Synthesis and enzymatic stability of PEGylated oligonucleotide duplexes and their self-assemblies with polyamidoamine dendrimers. Soft Matter 2008, 4, 294-302.

(47) Elsabahy, M.; Shrestha, R.; Clark, C.; Taylor, S.; Leonard, J.; Wooley, K. L. Multifunctional hierarchically assembled nanostructures as complex stage-wise dual-delivery systems for coincidental yet differential trafficking of siRNA and paclitaxel. Nano Lett. 2013, 13, $2172-2181$.

(48) Gao, H.; Elsabahy, M.; Giger, E. V.; Li, D.; Prud'homme, R. E.; Leroux, J. C. Aminated linear and star-shape poly(glycerol methacrylate)s: synthesis and self-assembling properties. Biomacromolecules 2010, 11, 889-895.

(49) Shrestha, R.; Elsabahy, M.; Luehmann, H.; Samarajeewa, S.; Florez-Malaver, S.; Lee, N. S.; Welch, M. J.; Liu, Y.; Wooley, K. L. Hierarchically assembled theranostic nanostructures for siRNA delivery and imaging applications. J. Am. Chem. Soc. 2012, 134, $17362-17365$. 